Editorial

\title{
Eli MacLaren
}

Three fascinating new contributions to Canadian publishing history lie ahead.

George Parker, recipient of the 2009 Marie Tremaine Medal, returns with a characteristically comprehensive account of the issues that English-Canadian book publishing faced in the decade between the end of the First World War and the Great Depression. The debate over the Copyright Act of I92I, the formation of the Canadian Authors Association, and the patterns of relations between Canadian publishers and their counterparts abroad all appear in vivid new detail. Equally characteristically, through exhaustive archival work, Janet B. Friskney pieces together the story of the Canadian Free Library for the Blind. Despite tenacious financial problems and the confusion of competing raised-letter tactile alphabets before the triumph of Braille, this organization managed to draw ever more Canadian blind people into the culture of the book, not only supplying them with inexpensive transcribed reading material but also verging on original publishing itself. Alison Rukavina uses the Sam Steele Collection, an important archive recently acquired by the University of Alberta, to examine an iconic Canadian's attempt to set down his memories for posterity. Steele, the quintessential Mountie, may also be the quintessential early Canadian author, for his desire to write a book collided with the necessity of having it published abroad, which entailed many unexpected inconveniences and frustrations.

All of these essays take Canadian publishing for the complex object that it is. The complexity is geographical: people in Montreal, Ottawa, Toronto, and Winnipeg are at the centre of attention, but events in Britain, the United States, Europe, and the world at large are shown to have influenced or constrained them. The complexity is also operational: publishing emerges as a tangle of expedient and idealistic activities, the threads of which cannot be separated from authors' motives, readers' needs, printers' interests, copyright law, librarians' and booksellers' contact with the public, and current events beyond the book trade, such as the First World War. Finally, the complexity is temporal, for although the early twentieth century is 
the period under scrutiny here, all of the essays situate their content among earlier causes and later effects. Nation, publication, and period thus at once come into sharp focus in their own right and yet unfold into what lies beyond them. The authors judiciously balance here against there and thereby fulfill the mandate of this journal as it has formed over the past fifty years - to explore the world of the book from a Canadian perspective.

The average reader of the Papers/Cahiers begins with the book reviews, however, and so I will conclude by inviting you to turn to those first. Heartfelt thanks to everyone listed on the masthead and to the members of the BSC council, without whose selfless work the Papers/Cahiers would soon cease. 
